\title{
Coupling project and system criteria for design coordination: A focus on competences manage- ment
}

\author{
Arz Wehbe $^{\mathrm{a}, \mathrm{b}^{*}}$, Christophe Merlo ${ }^{\mathrm{b}}$ and Véronique Pilnière
}

${ }^{a}$ Faculty of Arts and Sciences, Lebanese Canadian University (LCU), Aintoura, Keserwan, Lebanon

${ }^{b}$ University of Bordeaux, Estia Institute of Technology - IMS UMR 5218, Technopôle Izarbel, 64210 BIDART, France

${ }^{c}$ University of Bordeaux, Estia Institute of Technology, Technopôle Izarbel, 64210 BIDART, France

\section{CH R O N I C L E}

\section{Article history:}

Received: July 1, 2019

Received in revised format: July

22, 2019

Accepted: August 30, 2019

Available online: August 30, 2019

Keywords:

Collaborative design

Skills

Design management

Project management

Forecasting management of em-

ployment

\section{A B S T R A C T}

Over the past number of years, competence management has become a key issue for companies. Similarly, to the importance of knowledge management, competence management considers an individual's performance, based on his or her knowledge. Thus, knowledge management becomes an important aspect for companies to manage resources, through the ability of characterizing key competences and evaluating how they are improved through past experiences and roles, thus selecting project team members according to the respective existing skills. This paper focuses on the coordination of design activities in order to propose a tool dedicated to operation-level project managers to help prepare their technical teams based on the required skills. The goal is to enhance the effectiveness of the teams, as well as their performance in the short-term, as well as the longterm, while coordinating with the human resources department. This work is based on the results of the Aides et assisTances pour la conception, la conduite et leur coupLage par les connAissanceS - Help and support for design, coordination and their coupling by knowledge (ATLAS, 2008 - 2011). This project studies the coupling between systems design and management. We propose an initial tool to manage skills in a design project.

\section{Introduction}

There have been several studies and papers which addressed and studied the human and social dimensions of product design (Boujut \& Tiger, 2002; Perrin, 1999). The uniqueness of the design activity is that it is primarily a human activity, and not an automated one. In relevant research, the authors show that man is both a resource and an actor-engine for the design process (Merlo \& Girard, 2003). As a resource, it usually needs to be controlled, by assigning a set of tasks contributing to the overall development objective. But it is at the same time an actor (Crozier \& Friedberg, 1977) with a certain degree of autonomy as an engine of this design process, gradually built throughout the design. On the productdevelopment level, the logical project (Cleland \& Ireland, 2006) and the need for various stakeholders 
or partners to collaborate (Kvan, 2000) makes this an even more important human dimension. The control must provide such synchronization between design goals within a need analysis of the customer or the company regarding the future product and selection of human resources capable of performing the necessary tasks to meet these goals.

Managers often see their subordinates primarily as individuals with technical knowledge but do consider them mobilized too often in terms of skills. The concern that associating a person and a set of tasks in a logical short-term, may present several limitations such as: Experts required, beginners-level representatives on low-value activities, a significant turnover between each project, and even during long-term projects.

According to Hettiarachchi et al. (2016), software products change with time as a result of feature updates or as end user demands change. Alterations in the product or in its need would eventually require a reexamination of the software functionality in order to address or align with these modifications and specifications.

According to Galster and Avgeriou (2015), enterprise software systems, such as Enterprise Resources Planning software, are on the most part built in unassociated contexts. Nevertheless, various organizations use contrasting approaches and tactics to reach their objective. Consequently, many enterprise software systems are subject to specific changes and are customized in a way which allows them to take into consideration the context in which they are operating.

Conversely, human resource management, when structured, is seen in a long-term perspective (Minel et al., 2008). In fact, it matches human resources with business needs, not only in the short-term with recruitment and the potential dismissal of employees, but also in the long-term with proactive project management skills, life-long training and impending positions.

Regarding complex systems and product design, various models, methodologies and prototypes to integrate the features of the product as well as process and organization into a common logic of design coordination were presented in our study (Robin et al., 2007). This point of view has led to the reconciliation of the technical and human aspects with the structure of projects, stakeholders' activities and relevant task planning, as well as the pertaining design and performance assessment. It is recommended to lead a study on the techniques of incorporating stakeholders into competence-based team structuring and planning. The goal is to combine management skills in a comprehensive product-process-organization driving the design. In the following section, we present the framework for the coordination of product design. In section 3, we expand our vision of management skills. In the fourth section, we describe the ATLAS project (ATLAS, 2008 - 2011), which represents the foundation for our case study and shows how framework of coordination and competence management have been implemented in the demonstrator software developed in the ATLAS project (ATLAS, 2008 - 2011). Finally, in the last section, we cover new progress in management skills for businesses and we detail the possible headway of our work from a scientific point of view as operational practices through a new version of this software demonstrator.

\section{Design research method}

\subsection{Presentation of the project}

The ATLAS project (ATLAS, 2008 - 2011) has involved six French academic institutions, as well as two French industrial organizations which propose an instrumentation design activity based on the coupling of product and project design. Labeled by the Aerospace Valley pole, product design is studied here in an aeronautics context and therefore on the principles of engineering systems, (Bahill \& Briggs, 2001); International Council on Systems Engineering (INCOSE, 2015) among others.

The first company involved in the ATLAS project (ATLAS, 2008 - 2011) is an engineering company delivering services to industrial companies such as Airbus and its first level partners. This company is 
called here A. Innovation is the link between academics partners and a group of aeronautics companies interested in the results of the ATLAS project (ATLAS, 2008 - 2011).

The second company is a software editor proposing specific mathematical tools for simulation. It is directly concerned by the development of an ATLAS software demonstrator (ATLAS, 2008 - 2011) and its aim is to develop a new commercial activity in project management.

The implementation of a demonstrator software is an important initiative that took place in 2011. Its aim is to implement methods which ensure the coupling of the object of design (the product or system) as well as the process of realization (the design project) in a collaborative environment for concurrent engineering (Prasad, 1996).

The desired result will provide a consistent and efficient decision-making process, based on information provided by these two dimensions, and consolidated by the aggregation of information from the detailed structuring of the projects and the system.

\subsection{Research method}

Competence management is a research question that comes from a long scientific process. To better understand the context and the interest of our proposals, we must consider the existing collaborations between the different academic partners. The research methodology is therefore a combination of exploratory and conceptual work in the research-action approach, as shown in Fig. 1.

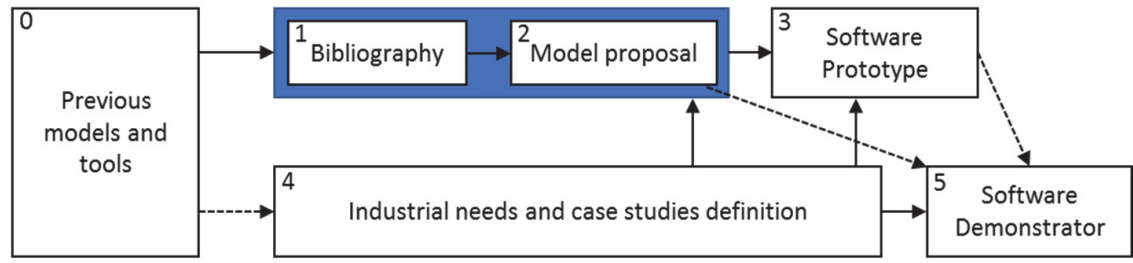

Fig. 1. Research Methodology

ATLAS project academic consortium (ATLAS, 2008 - 2011) is the result of several years of academic research: Two of the partners were specialized in design coordination, another two were into product and engineering system modeling, one in project management and another into constraint modeling and problem-solving methods. Some of the different collaborations that were proposed:

- Models for design coordination combining product, process and organizations modeling at a global level;

- Models for product/systems modeling according to system engineering standard;

- Models for project scheduling;

- Tools and techniques to explore solution spaces using constraint based approaches.

- Main results are briefly described in the following sections. Within ATLAS project (ATLAS, 2008 - 2011), we have adopted the following research method:

o First step: Synthesis of previous academic work, state of the art then proposal of an integrated model;

o Second step: Development of a research prototype to show how the concepts of the model can be used;

○ Third step: Analysis of industrial needs and definition of case studies;

- Fourth step: Analysis of needs and case studies for consolidating the models and the prototype;

o Fifth step: Design and implementation of an industrial demonstrator with restricted but operational functions in order for it to be tested by industrial organizations using the case studies.

Steps 1, 2 and 4 correspond to a traditional concept-to-application scientific approach, while steps 3 and 5 correspond to a research-action approach. Figure 1 illustrates the interactions between these two approaches. 


\subsection{ATLAS demonstrator design and implementation}

The first prototype has been developed for academic purposes, based on an existing tool dedicated to product modeling with Web-based interface. The implantation platform is a Ruby on Rails framework. This tool is still used actually by several academic partners.

The demonstrator has been implemented by the software editor company, using the same framework. The design method is user-centered: Initial interviews and group workshop allow defining:

- Needs at a conceptual level for modeling proposal;

- Interactions then functions wanted by the future users;

- And case studies for both the academic prototype and industrial demonstrator.

Based on industrial needs, different design choices have been made for the demonstrator, even if the same implantation framework has been selected for reusing reasons. The demonstrator is a standalone software that must be installed on a personal computer, but it embeds communication protocols to access a unique distant database. The interface must look as day-to-day applications for users on their PCs.

In the following section, we develop a state of the art of models and previous scientific work (step 0 of our research methodology) on which have been based the specifications of the software demonstrator.

\section{Coordinating product design}

Product design projects performance depends on the ability to coordinate and control the collaboration between the numerous participating stakeholders: e.g. designers, experts from different disciplines and with different experiences, and external partners. Coordination and control of engineering design are part of a global approach of the development of new products which requires the need to identify the different situations occurring during the design process and to allocate adequate resources to satisfy design objectives.

Many studies have attempted to pinpoint and address best practices and strategies developed by enterprises (Balbontin et al., 2000) in order to better the success of new products. They take into consideration several circumstances, such as environmental challenges, markets and customer characteristics, marketing processes, product characteristics, new product development processes, organizational characteristics and corporate culture, learning practices, and performance.

A project manager now has a wide range of criteria to take into account in order to control all aspects of a project such as the product development steps, objectives and results, tasks and scheduling, resources, expert skills, actors' network, levels of interest, collaborative guidelines, and heterogeneous collective and individual objectives.

On the one hand in conclusive research (Coates, Whitfield, Duffy, \& Hi, 2000), authors suggest that task management, scheduling, planning, and resource management are the most important issues when it comes to operational coordination. Clearly, a project manager intends to apply these aspects to control the design process.

On the other hand, collaboration between designers offers the possibility of sharing specialist knowledge and capabilities (Martinez, Fouletier, Park, \& Favrel, 2001), (Giannini, Monti, Biondi, Bonfatti, \& Moanari, 2002). For the project manager, anticipating collaboration is difficult to take into account in the everyday life of a project. The main problem is that of proposing to design actors the best context as possible (e.g. objectives, information, resources, tools, methods) in order to foster collaboration that will facilitate reaching project objectives.

In design project management, the progress control of the design process can be defined as the understanding of existing design situations (in the real world) in order to evaluate them and take decisions that 
will modify and improve future processes, according to design objectives given by customer specifications or based on the company strategy. The control problem here is a problem of decision-making taken by a "decision center" - to support designers - represented by a design center - in their activities (Girard \& Doumeingts, 2004) in order for them to achieve an objective in a specific context (Fig. 2). Each design activity has "input" and "output" information which transform the design process as well as the product definition. Actors use the "input" in order to produce the "output", to achieve their activity and have "support" namely: Human and material resources and knowledge to help them in their work.

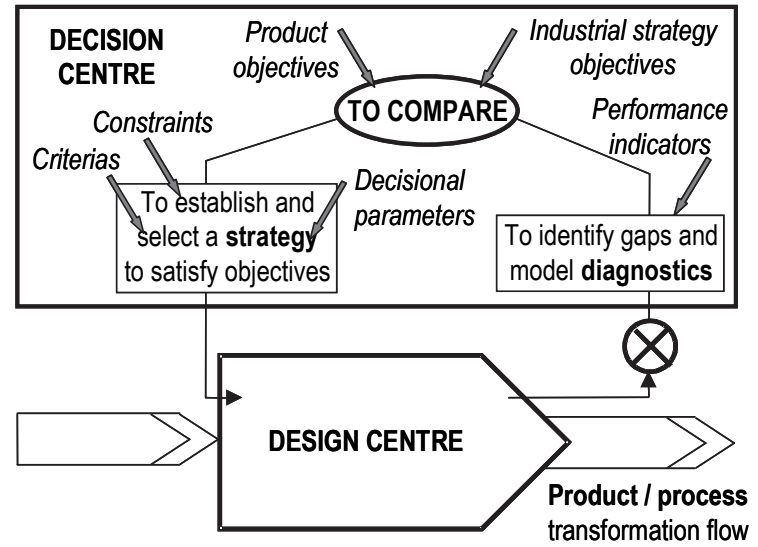

Fig. 2. Coordination Model in the Design System

This approach has been developed (Girard \& Doumeingts, 2004) as the GRAI R \& D approach and implemented through the GRAI Engineering methodology (Merlo \& Girard, 2003). It relates to the deployment of design principles based on the integration of three elements: The product, the process and the organization.

For decision making, project managers - from a decision center - need to identify effective action levers which will influence the design process thus increasing design performance. In this context, a project manager coordinates (Figure 2) by analyzing the requirements from the customer, after which they define the project team as the design center team, with its internal organization (Mintzberg, 1990). They then define the project phases and activities in each sub-phase, and then define a 'design frame' to control the project progress and finally apply this design frame. Periodically they control project progress and make the adequate modifications in accordance with the results and the design objectives.

As design projects may be large and complex, a project manager may create or define several sub-projects with local projects or task managers. As a consequence, the previous model is a recursive model. A design center may be divided into new couples (decision center, design center) representing such subprojects. The coordination between a level-n decision center and level- $n+1$ decision centers is regulated through specific 'decision frames' in order that level-n+1 managers be able to define their own design frames.

The project IPPOP (Roucoules, et al., 2006) has led to an operational version of these control concepts while offering a first software prototype that focuses on these concepts. The PEGASE application (Robin, Merlo, \& Girard, 2007) has continued this work by integrating a stronger structuring of the company to structure the project. The ATLAS project (ATLAS, 2008 - 2011) introduced hereafter is part of this logic.

\section{Management of resources by competences}

The definition of the concept of "competences" is necessary before tackling the integration of resources in activities pertaining to control design, in order to be able to question the management of these same resources. 


\subsection{Common definition for competences}

What is meant by "competence"? Answering this question does not come naturally. The meaning of competence has long been under discussion.

De Witte (1994) regards competences as a concept that doesn't have a distinct definition, and emphasizes the necessity of agreeing on a common definition for clarity (De Witte, 1994). This idea underscores the fact that competence is never given directly to see: For the author, competences are not detectable through a microscope.

Despite the inability to agree on a universal definition of competences, it may be regarded as a combination of knowledge, know-how, and skills. Le Boterf (2010) declares that competences are not a state and they are linked to action (Le Boterf G. , 2010). In his opinion, competences are the outcome of three factors: Knowing how to act, willing to act, and possessing the power to do so. This means that someone who qualifies would know how to support and finance the relevant resources, despite a context which may seem without incentive at times, by inferring what is involved with regards to responsibility and risk taking.

In 2004, Masson and Parlier identify four defining characteristics of competence: It is operative and finalized (it is inseparable from an activity), it is learned (a result of personal or social building), it is structured (it combines knowing how to act, willing to act and the power of acting), then it is abstract and hypothetical (the competence is not directly observable but only its consequences are) (Masson \& Parlier, 2004).

Michel (1993) considers a competence as an ability to solve problems in a given context and in an efficient way (Michel, 1993). For our part, we will retain the definition proposed by (Boumane, Talbi, Tahon, \& Bouami, 2006) that incorporates the definitions of the other authors. "Competence is the ability of a person (actor) to act and react with the required relevance to perform an activity in a work situation". The actor is at the center of the process of selecting, combining and mobilizing their knowledge, skills, abilities and behaviors on the one hand, and environmental resources on the other hand, in order to accomplish a mission defined by the company.

However, it seems necessary to add to this definition the idea of "social recognition" developed by (Le Boterf G. , 1994), provided that the competence is "knowing how to act".

While it is clear that competence, as we have seen, is an individual behavior, it should be extended to a more collective dimension. It is unfound to dissociate these two dimensions, as they are interdependent in the design processes, and they call for many actors.

\subsection{Collective competences}

Based on contribution from (Le Boterf G. , 2010), we consider that the cumulative competences are an integration of individual competences. "In the collective design situations, the aim of the process (the intended purpose, the" thing "to do ...) and the process itself (how each one is relevant to the other ...) are built by mutual influence" (Hatchuel A. , 2008). In fact, in such processes, "actors cannot limit their contributions, and must run their activities according to the project or the other actors' evolution." The progress of collective competences depends on reciprocal learning (Hatchuel A. , 1995) in which the action of each actor depends on all the learning actors.

In the process of cooperation that occurs in the course of work (De Terssac, 2002) during the design activities, other learning rules come about among the concerned actors: "Learning is therefore necessary at any time and requires exchanges between performers and makers."

If the competences appear well in the center of human resource management, the different aspects that we have just developed highlight the complexity of managing these competences (Minet, Parlier, \& De Witte, 1994). Often, collective competences management is hardly taken into account in companies, unlike the individual competence's management. 


\subsection{Competences management in companies}

The management of competences is a methodology that primarily involves human resources management, which usually replaces traditional management based on position and functions related to the location (Retour, 2002). In fact, in small and middle-sized companies, the establishment of a project unit will depend on a single individual, such as the entrepreneur, the technical director or the head of the research department. The size of the team will also be diminished, and the selection of tasks will not amplify, since the nature of the tasks will be directly related to the ranking of the personnel. Management competences rely on the concept of "versatility" which is reduced to simple availability management for the actors.

Among the advantages associated with this type of management, included is the establishment of a common and standardized vision for all employees of the company. This vision leads initially to the establishment of training policy competences. It can be followed by the establishment of an evaluation by competences of the employees. They are necessary in order to establish competences planning. A final step would be to combine competence and compensation, which is still a limited practice (Gilbert, 1994). The notion of performance is also very present in this competence approach, as far as decision makers are considered (Defelix \& Retour, 2003).

This work shows that competences management is applied for team building projects and some team members are distributed on specific tasks, since competences are associated with an activity and a level of competence (Gilbert, 2003). A company which has legitimate human resources, competences management is distributed among people from different backgrounds, especially when several companies are involved in collaborative processes (Boucher, 2009). Technical managers choose specialists based on the qualities or experiences they have already acquired or on which they were advised. Planning or financial project managers are also interested in questions of availability, knowledge-based recruitment or level of competences to be determined. The Human Resources function manages the needs of people as profiles of knowledge / competences, through internal or external recruitment. Beyond the management of competences and operational management, long-term management of these design competences is too often the responsibility of the project manager when starting a project that does not appear systematically in the primary concerns of the company. Experiences gained in various projects, but also in varying functions throughout a career, can then be considered to establish and formalize training schemes in the short term, while also managing the long-term career. Practices are based mostly on mapping competences in 4 distinct levels (Veltz \& Zarifian, 1994): Competences necessary for a specific position, competences used by an employee in this position, actual competences gained by the employee and the potential employee's competences, thus allowing the employee and the company to consider a career development path.

Further to our work with companies of diverse sizes and sectors, we found that there is a big difference in competences from one company to another.

\section{ATLAS Project results}

The ATLAS project represents a significant part of our work and study, on the design process and its coordination.

\subsection{Architecture of the ATLAS demonstrator}

The different models developed to achieve the objectives of coupling have been presented in various research publications (Aldanondo, et al., 2008). The mechanisms that implement them are based on knowledge modeling concepts such as system, reuse, and performance evaluation in the form of variables, constraint programming and feedback.

The demonstrator program targets users who are involved in system design and users who are responsible for project planning. It has two main modules: 
- The "system design" module: This module allows designers to define a system according to the principles engineering system method by decomposing a system into subsystems. It also supports the production of the deliverables associated with each step of the design process. This module includes the management of system concepts that allow the capitalization on design knowledge and its reuse in future projects.

- The "project management" module: This module allows the definition of sequence of tasks that detail the design process to guarantee the planning and monitoring. It relies on a process model that supports the engineering system process advocated in the context of The American National Standards Institute/Electronic Industries Alliance (ANSI/EIA632) (ANSI/EIA-632, 1998) norm. So it provides: Mechanisms of decomposition of a project into sub-projects; mechanisms of management of different project alternatives; and mechanisms for integrating proposed subsystems into upper system. It includes the allocation of resources, including human, for each of the tasks.

Each system and each project have associated variables which specify the indicators on which the system will be evaluated (and therefore each subsystem) and the project (and each sub-project). Performance targets and constraints can be set by system and project managers and then be checked throughout the design progress and lifecycle.

A third "project coordination" module focuses on the overall management of this dual system design and project evaluation is used to track the performance achieved by referring to the values of variables and offering a synthetic scoreboard, combining variables, systems and projects. This module centralizes the exchange between project managers and the system by integrating an internal messaging system. It tracks the decisions and relevant justification.

The coupling is provided by various mechanisms built directly in the demonstrator, either independently or integrated in the modules implemented.

The general planning of the demonstrator is seen in Figure 3, which shows the relationship between modules. Reliable external apparatus are connected to the ATLAS demonstrator:

- A scheduler to generate visualization of tasks scheduling;

- A dedicated module for "messages" management, especially alerts;

- Constraint propagation engine (COFIADE, proposed by the Centre Génie Industriel from the Ecole des Mines d'Albi-Carmaux) for managing rules coupling system constraints and project constraints;

- And a "feedback" management module for storing models and experience of a project and then reusing it (T-REX, proposed by the École nationale d'ingénieurs de Tarbes - ENI of Tarbes).

Competence management is integrated into the "project management" module, and specific parameters are used to define specific constraints that are managed with COFIADE through the "coupling" infrastructure.

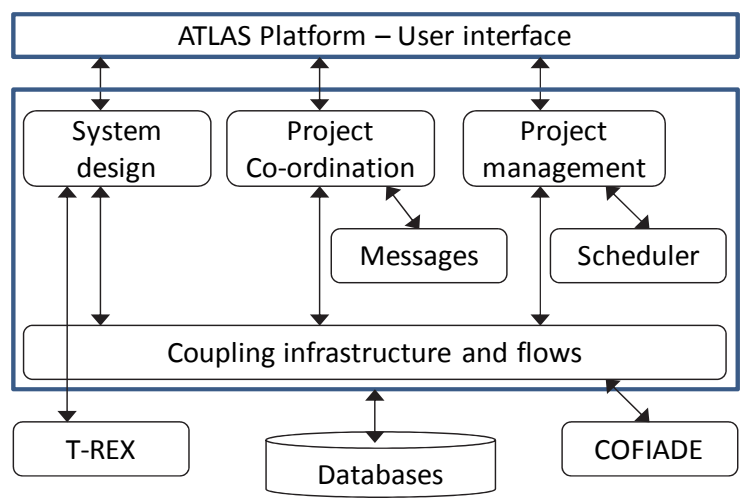

Fig. 3. Architecture of ATLAS Prototype 


\subsection{ATLAS control design implemented approach}

The design control is based on the integrated product-process-organization PPO model (Roucoules, et al., 2006) as a result of previous work, which is also our hypothesis at the beginning of the ATLAS project (ATLAS, 2008 - 2011). It is based on the structural decomposition of projects into sub-projects. Then at each project level the distinction is made between the decision system and the technological system. From an operational perspective, deduced from the concepts mentioned in Figure 2, the system includes different decision makers in charge of coordinating their project level, and thus coordinating the activities of designers of the project level: The design teams represent the technological system of this level.

Considering the way industrial companies manage an airplane development program, there are three key people in charge of the project:

- The system managers SM, in charge of the systems/subsystems development;

- The planning managers PM, in charge of controlling project progress such as scheduling, costs and resources allocation;

- And the project director PD that launches the project and appoints the heads of the first level.

This control mode helps in part, to manage the coordination of the design. Inspired by the organizational model of the PPO model (Figure 4) but adapted to specific needs of aeronautics partners of the ATLAS project (ATLAS, 2008 - 2011), each level beyond the first is identical and repeated for each new subproject.

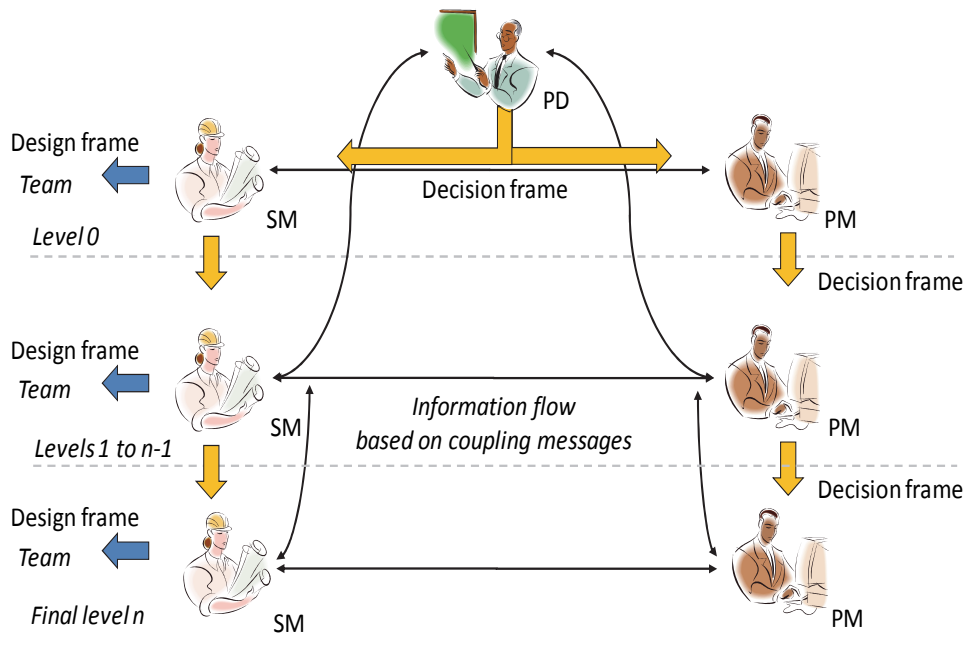

$\mathrm{NB}: \mathrm{SM}=$ System Manager et $\mathrm{PM}=$ Project Manager $-\mathrm{PD}=$ Project Director

Fig. 4. ATLAS Organizational Module

The coupling is designed to facilitate the impact of decisions made in each of the two-dimensional systems and projects, and the exchange of relevant information needed for comprehensive, relevant and justified decision-making, in a collective context if possible. Different coupling modes have been derived and identified (Aldanondo, et al., 2008) from the structured models coming from previous works and literature. Then each one has been applied through the case studies before a critical evaluation by the companies. Here are some examples of the consolidated coupling modes:

- Ensure the bidirectional relationship between the system entities and the project parameters on one hand, and between system alternatives and project alternatives on the other hand: The hypothesis used in the ATLAS project (ATLAS, 2008 - 2011) is based on the fact that a system is always in correspondence with a project. As a consequence, the system structure corresponds to the project structure until the system design is sufficiently known and mastered for no longer needing to generate sub-projects. 
- Alert when there is a decision for stopping the decomposition of systems into subsystems; this interrupts the decomposition of the project as well and triggers a predefined stage of finalizing the design before starting the stages of integration of validated components or systems.

- Alert of a decision for reuse of entities (or alternatives entities): If an existing system is chosen to be reused in the current design, then the planning manager is advised to potentially exploit the archived project schedule, and vice versa.

- Propagate constraint changes on variables, between both planning managers and system managers.

- Propagate the change status of a system entity or a project task towards relevant managers.

- Synthesize via the scoreboard, all the constraints that apply to variables, taking into account a mechanism of aggregation of variables corresponding to lower levels.

For these different coupling modes, the system manager determines the design goals for their team and disseminates them in impediments that apply on the variables they have selected for the systems expected to be designed. The planning manager does the same with project specific targets (budget, available resources, and processes / activities schedules). The two categories of managers must work together to describe the activities that detail the predetermined process and verify the allocation of sufficient resources. Each of these individuals or stakeholders may be dependent on a team to aid them in coming up with their decision (excluded from Figure 4).

All members then monitor the progression of the design; firstly, overseeing design activities and constraints for a system design, and then secondly, checking advances in milestones, costs and other project limitations. The couplings used (alerts and scoreboard) assist in the identification of gaps and non-compliance restrictions, resulting in managers collaborating to make new decisions.

This segment analyses the issue of competence management and its application in the ATLAS demonstrator.

\subsection{Managing competences within the ATLAS demonstrator}

As part of a computer implementation as proposed in ATLAS, it seems necessary to propose a flexible and demanding mechanism, so as to enable each company to use the concept of competences depending on their needs and how it works properly. In a first step, the integrated models allow us to propose a basic way to manage human resources: The program director defines a first level team by indicating the name and the type of the members, selecting a main system manager and a main planning manager. Then at each system level planning managers together define their own team in the same way. This basic approach does not satisfy industrial companies:

- A system manager has to propose a team by defining what he needs considering several technical criteria,

- A planning manager has to propose team members available according to cost and duration criteria.

Because of these considerations and the organizational model chosen, we proposed to extend the model for better competences management and the approach to manage them.

For this reason, the demonstrator has been configured to allow the association between competences and individuals. Competences are grouped into different types to simplify their access by the responsible individuals. Types can be predefined through the configuration module of the demonstrator so that it can be adapted to the core competences of a company. Fig. 5 shows all the competences and types (adaptational, coordinational, social and relational, then technical) currently defined. We propose this definition according to the decomposition of competences - knowledge, know-how and soft skills - proposed in 1990 by Mandon (Mandon, 1990), and the distinction between embedded resources and resources of the environment (Le Boterf G. , 2010), adapted to the design context. 
The system manager will use this definition to define what kind of individual he needs for his team according to the tasks he has to do.

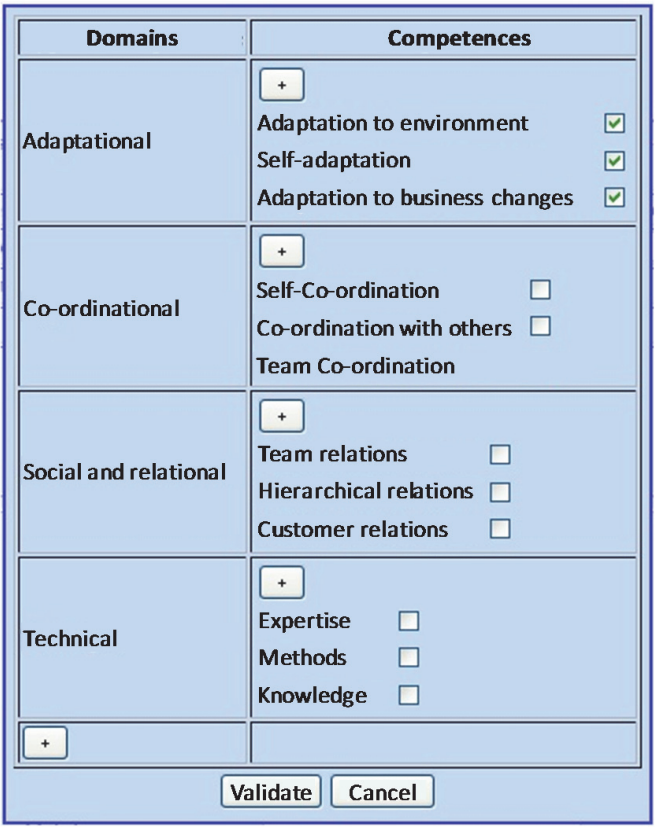

Fig. 5. Competences and Type of Competences

Fig. 6 below shows how human resources management is done and the allocation of competences within the demonstrator. This kind of information is maintained and used by the planning manager to allocate the right individual for the system manager.

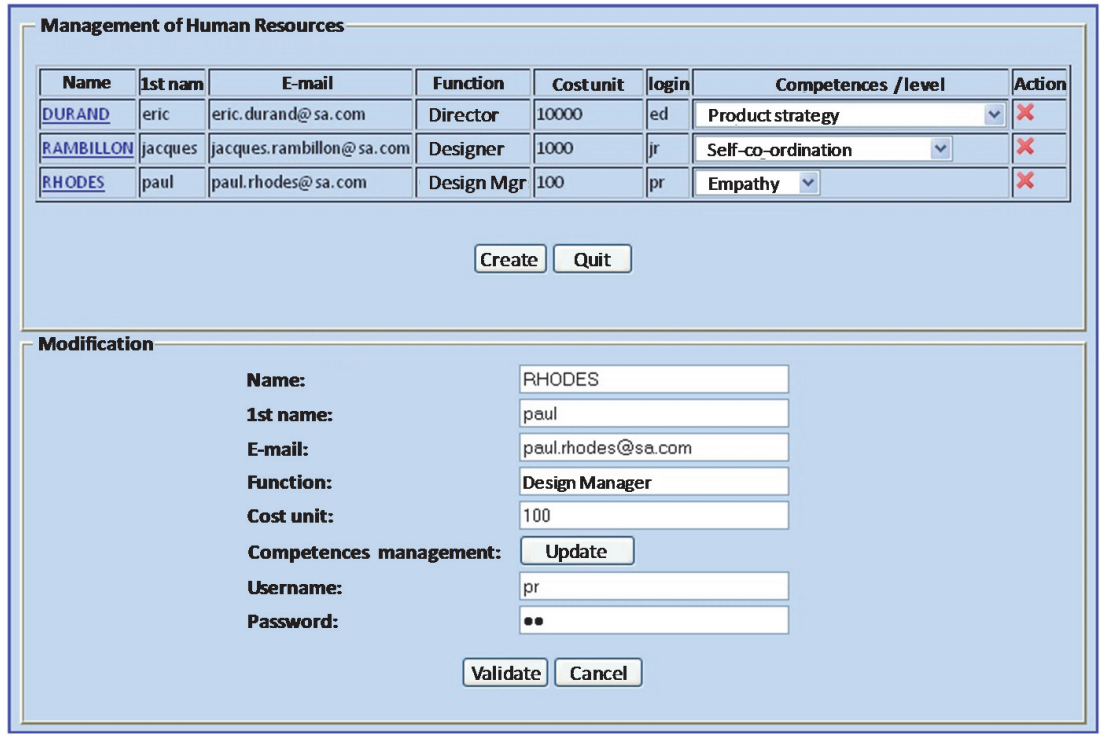

Fig. 6. Competences and Human Resources

Finally, Fig. 7 illustrates the work of the project manager when creating the project, with the bottom screen for selecting competencies for the system manager and for the project lead, who selects a list of individuals who can assume the roles of leaders. The same applies for sub-projects and for setting up the project team. Exchanges occur between project and system managers at the upper level, to validate these choices, based on the scoreboards of performance indicators of the project. 


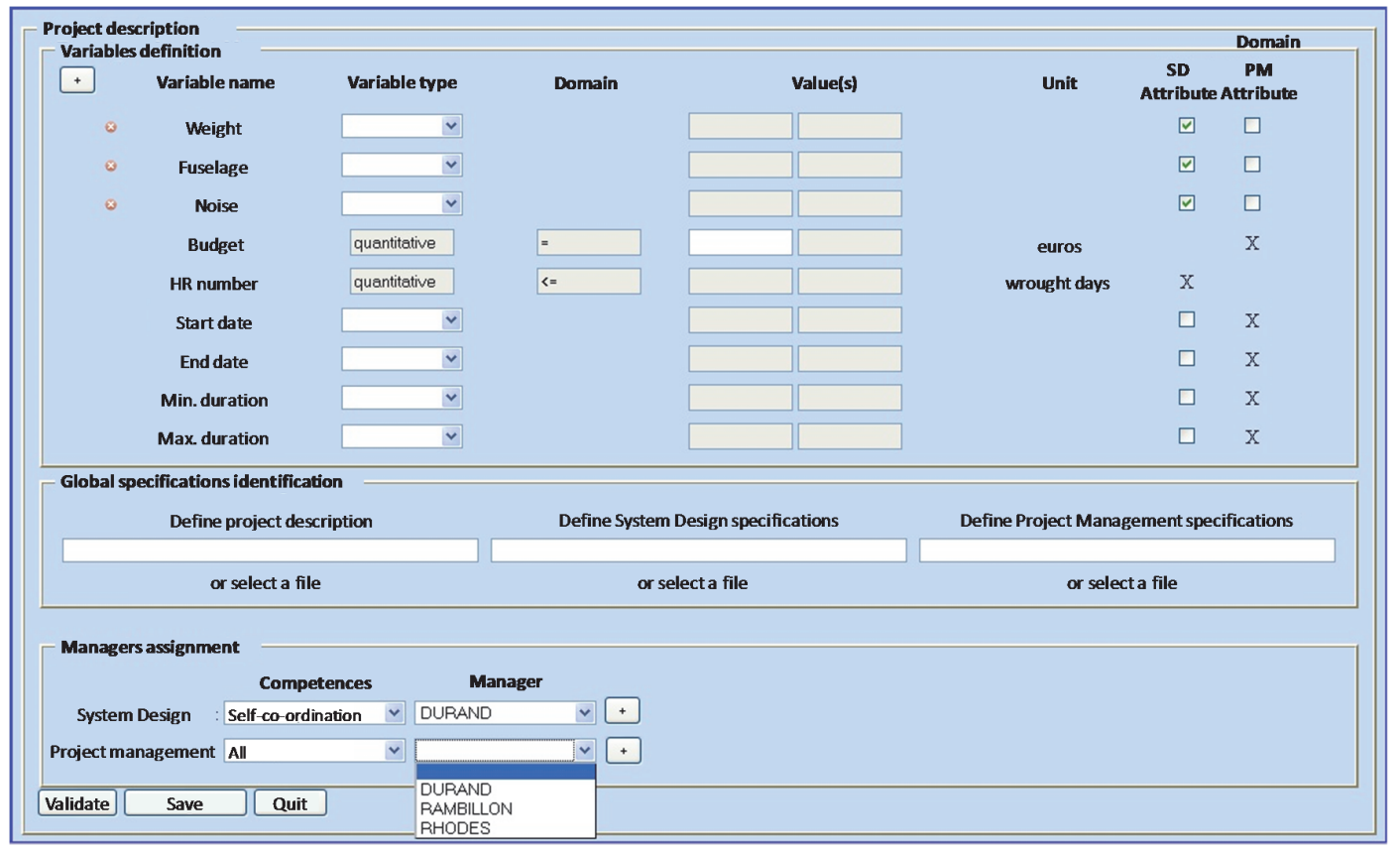

Fig. 7. Competences and Granting

Finally, a system manager is considered as responsible for defining their team in terms of needs, while a planning manager is responsible for checking the availability and cost of human resources to be mobilized. The coupling of the different parameters characterizing an individual and their competences represent a way to share their point of view through a direct dialogue that can be supported by the "message" module of the demonstrator. An individual is then assigned to a project if both leaders confirm that choice.

As an example, this process of defining needs then proposing resources corresponding to the needs may lead to simulations before choices. If there is no individual corresponding to the needs defined by the system manager, the planning manager will be able:

- To propose an individual with different skills, some with a higher level than needed with a cost increase, or some with a lower level with a time scheduling increase: In this situation they will be able to share with the system manager the impact on the quality of the allocated tasks and on the project cost and scheduling;

- To propose an individual that must be removed from an already allocated task with the constraint of being replaced by another individual: Impact on the project is also a way to lead to the best possible solution.

That is why in the final version of the demonstrator the "scheduler" module we have introduced different visualization processes for showing the existing schedule but also simulation schedules before choosing one. In the same way, the scoreboards of the coordination module can be associated with the simulation schedules in order to allow managers to evaluate each constraint and their impact on the project's main parameters.

\section{Results and Discussion}

As mentioned previously, case studies have been defined with industrial partners. Each one corresponds to a situation that rebuilds real situations encountered in real projects. Two examples have been used to characterize these case studies: The first one is a simple system corresponding to the development of an 
electronic key, and the second one is based on the first levels of an airplane development. The first key example has been used to validate decision processes for selecting the best technical solutions between several possible ones. The second airplane example has been used to validate the interactions between project constraints and system design choices. This second example includes competences case studies.

The case studies have been implemented as scenarios describing the different tasks to do, with the required inputs / outputs. These scenarios have been built with information captured during interviews with the industrial companies before their validation by the same companies.

For each example, a specific database has been filled with the initial inputs, and then each company has been invited to apply the scenarios with the TALAS demonstrator. Then a new interview has been made to formulate the following feedback: What bugs have been identified? What are some useful improvements with the use of the demonstrator? What are the improvements of the methodology underlined by the scenarios?

The problems encountered when using the demonstrator are operational problems that are not linked to our research proposals. As the demonstrator was not dedicated to being sold, they have not been considered.

Considering improvements of the software, operational ones such as modifications of the Man-Machine Interface have been archived for a future tool. Some improvements have been introduced in the second version of the demonstrator. Two types of improvements have been asked:

- The modification of parameters defining some concepts: e.g. improving the list of competences or the types of competencies (for example the level of experience), adding a global but manual maturity parameter to a system and to a project in order to represent the fact that such a system or project has already been achieved in previous system development;

- The modification of the tasks from the scenarios in order to automate them. For example, in order to select an individual, we first propose to visualize the whole list of available resources only. Then after feedback we modified this task by generating a list of people available but with an average level of similarity with the needed competences, so the list is shorter. We add a second list of people with a high level of similarity but who are not available as mentioned in section 5.3.

Finally, considering the third question on methodology improvement, this demonstrator deserves to integrate a concrete management of competences in the design process, but it has some limitations.

First, it would be interesting to incorporate more accurately the situations that mobilize certain competences. For example in Figure 5, the situation in which one person is able to adapt them self (competence "self-adaptation") is generic and not specified: Having self-adaptation abilities does not mean that it is true for all situations that can be encountered within a system development project. As we have seen, a competence can only be measured for a given situation. On the same idea, the "Adapt to the environment" competence does not specify all the personnel and external resources that the person is supposed to mobilize (Le Boterf G. , 2010).

Furthermore, the concept of competences levels is necessary but not implemented from this first prototype, as we have seen before, in order to consider competences scheduling. In this fashion, it would be possible to evaluate the level required to complete an activity, the level mobilized by an actor in this activity, or the potential level reached by this actor on terms to be defined (e.g. training). In this way the project manager can master more expected performance by the employees he selects, which directly impacts the performance expected in the project itself.

Thirdly, an inherent difficulty to the complexity of the competence lies in identifying informal competences. They often refer to "embedded knowledge" often implicit, reflected in the speech with "you can see" "you feel good" reflecting for the person the difficulty or the impossibility of accessing such of the type of competence. 
Finally, and more broadly, if this demonstrator is only a tool, it could be very useful as a source of practical information for planning of jobs and competences. That is the main result of this work: The software editor company has been developing a specific tool for project and resources management, using a professional environment that allows data sharing with a famous and worldwide software suite, in order to sell it to its customers. Of course, this commercial tool does not integrate the system modeling and by consequence the coupling approach. But main concepts of project and resource management have been reused.

Considering now the research methodology, the interest of combining traditional scientific proposals to a research-action approach based here on interviews, case studies, experiments and feedback analysis is effective. The traditional approach can be assimilated to a top-down method from scientists that propose then apply, while research-action can be compared to a bottom method that requires a confrontation with the traditional approach not to be managed only at an engineering level.

This bottom-up method, implemented in parallel to the top-down method, allows us to improve both concepts and methods that we had proposed in order to make our proposals more relevant before being applied. At the same time, the top-down method allows us to have a strong baseline for the framework we want to involve industrial companies with. We think that it helped us to focus on precise and strong results in the limited timeline of this thirty-month project.

\section{Conclusion}

In project management, and the project management of product development, human resources are considered as an essential element of project manager activities. Focusing on issues of allocation and availability, these operational concerns are not always aligned with the concerns of long-term human resource departments, for which competences management is an essential tool.

By relying on the results of the ATLAS project (ATLAS, 2008 - 2011), focusing on the coupling between system design and management of design projects, we have proposed a first pragmatic mechanism for extending the simple management of resources assignment and availability by including the competences dimension. Competences classified by types thus become the link between an individual defined by his competences, and the ability to select a resource through competences needs. The organizational model of decision making among managers can oversee the process of decision which transforms this need of competences in a planned and validated allocation against performance indicators of the project.

The case studies implemented with the industrial companies validate the concepts of this integrated framework dedicated to the system engineering and project management modeling using constraintbased coupling methods. Nevertheless, project management concepts are still generic concepts such as cost, resource and competences management and task scheduling. We are actually working on extending these concepts by taking into account uncertainty and risk management in order to improve the analysis of system / project choices and better analyze the impact of possible decisions.

\section{References}

Aldanondo, M., Vareilles, E., Djefel, M., Baron, C., Auriol, G., Geneste, L., \& Zolghadri, M. (2008). Vers un couplage de la conception d'un produit avec la planification de son développement [Towards a matching between product design and the planning for its development]. 7e conférence internationale de Modélisation et Simulation, MOSIM'08. Paris, France.

ANSI/EIA-632. (1998). Electronic Industries Alliance, Processes for Engineeringa System.

ATLAS. (2008 - 2011). Aides et assisTances pour la conception, la conduite et leur coupLage par les connAissanceS - Help and support for design, coordination and their coupling by knowledge.

Bahill, T., \& Briggs, C. (2001). The systems engineering started in the middle process: A consensus of systems engineers and project managers. Systems Engineering, 4(2), 156-167. 
Balbontin, A., Yazdani, B., Cooper, R., \& Souder, W. (2000). New product development practices in American and British firms. Technovation, 20(5), 257-274. doi:10.1016/S0166-4972(99)00136-4

Boucher, X. (2009, April 18). Collaborative Decision-making Support System to Enhance Competencies within Enterprise Networks. Journal of Decision Systems, 18(3), 319-346.

Boujut, J.-F., \& Tiger, H. (2002). A sociotechnical research method for analyzing and instrumenting the design activity. Journal of Design Research, 2(2), 121-134.

Boumane, A., Talbi, A., Tahon, C., \& Bouami, D. (2006). Contribution à la modélisation de la compétence [Modeling contribution of competencies]. Ge conférence internationale de Modélisation et SIMulation, MOSIM'06. Rabat, Maroc.

Cleland, D., \& Ireland, L. (2006). Project management: strategic design and implementation (5 ed.). London: McGraw-Hill Gb.

Coates, G., Whitfield, R., Duffy, A., \& Hi, B. (2000). Co-ordination approaches and systems. Part II. An operational perspective. Research in Engineering Design, 12, 73-89.

Crozier, M., \& Friedberg, E. (1977). L'acteur et le système [The actor and the system]. (Seuil, Ed.) Paris.

De Terssac, G. (2002). Le travail : une aventure collective [Work: a Global advanture] (Octarès ed.). Toulouse, France: Octarès.

De Witte, S. (1994). La notion de compétences : problèmes d'approches, dans La compétence, mythe, construction ou réalité ? [The competencies conception: approaches problems, in competencies, myth, construction or reality?]. In F. Minet, M. Palier, \& S. De Witte (Eds.). Paris: L'Harmattan.

Defelix, C., \& Retour, D. (2003). La gestion des compétences dans la stratégie de croissance d'une PME innovante : le cas Microtek [Competencies management in the growth strategy of an innovative SME: the Microtek case]. Revue Internationale PME, 16, 3-4.

Galster, M., \& Avgeriou, P. (2015). An industrial case study on variability handling in large enterprise software systems. Journal of Information and Software Technology, 60, 16-31.

Giannini, F., Monti, M., Biondi, D., Bonfatti, F., \& Moanari, P. (2002, December 1). A modelling tool for the management of product data in a co-design environment. Computer Aided Design, 34(14), 1063-1073.

Gilbert, P. (1994). La gestion des compétences : du discours à la construction de nouvelles pratiques sociales [Management of competences: from discourse to the construction of new social practices]. In C. Piganiol-Jacquet, Analyses et controverses en gestion des ressources humaines (pp. 213-230). L'Harmattan.

Gilbert, P. (2003). Jalons pour une histoire de la gestion des compétences [Milestones for a history of skills management]. In A. Klarsfeld, \& E. Oiry, Gérer les compétences : des instruments aux processus : cas d'entreprises et perspectives théoriques (pp. 11-32). Paris, France: Vuibert.

Girard, P., \& Doumeingts, G. (2004, March ). Modelling of the engineering design system to improve performance. Computers \& Industrial Engineering, 46(1), 43-67.

Hatchuel, A. (1995). Les marchés à prescripteurs. Crise de l'échange et genèse sociale [Marching toward prescribers]. In A. Jacob, \& H. Verin, L'inscription sociale du marché (L'Harmattan ed., pp. 205225). Paris, France.

Hatchuel, A. (2008). Coopération et conception collective - Variété et crises des rapports de prescription [Cooperation and Collective Design - Variety and Crisis of Prescription Reporting]. In G. De Terssac, E. Friedberg, G. De Terssac, \& E. Friedberg (Eds.), Coopération et Conception (Octares ed., pp. 101121). Toulouse, France.

Hettiarachchi, C., Do, H., \& Choi, B. (2016). Risk-based test case prioritization using a fuzzy expert system. (Elsevier, Ed.) Journal of Information and Software Technology, 69, 1-15.

INCOSE. (2015). Systems Engineering Handbook: A Guide for System Life Cycle Processes and Activities (4th ed.). (D. Walden, G. Roedler, K. Forsberg, R. Hamelin, \& T. Shortell, Eds.) San Diego, USA: John Wiley \& Sons.

Kvan, T. (2000, July ). Collaborative design: what is it? (Elsevier, Ed.) Automation in Construction, 9(4), 409-415.

Le Boterf, G. (1994). De la Compétence, essai sur un attracteur étrange [Competence, try on a strange attractor]. Paris, France: Organisation. 
Le Boterf, G. (2010). Construire les compétences individuelles et collectives [Tailor individual and collective skills]. Paris, France: Organisation.

Mandon, N. (1990). Analyse des emplois et gestion anticipée des compétences [Management of anticipated competencies and job analysis ]. Centre d'Etudes et de Recherche sur les Qualifications (CEREQ - Bref), Marseille, France.

Martinez, M., Fouletier, P., Park, K., \& Favrel, J. (2001, December ). Virtual enterprise organisation, evolution and control. International Journal of Production Economics, 74(1 - 3), 225-238.

Masson, A., \& Parlier, M. (2004). Les démarches compétence [The competence approaches]. Paris, France: ANACT.

Merlo, C., \& Girard, P. (2003). GRAI Engineering: A Knowledge Modelling Method to Co-ordinate Engineering Design. International CIRP Design . Grenoble, France.

Michel, S. (1993). Sens et contresens des bilans de compétences [Advantages and disadvantages of competencies listings] (Liaisons sociales ed.). Paris, France.

Minel, S., Merlo, C., \& Zolghadri, M. (2008). Analysing collaboration in order to propose a framework for supporting management of co-design network. ERIMA'08. Porto, Portugal.

Minet, F., Parlier, M., \& De Witte, S. (1994). La compétence, mythe, construction ou réalité ? [Competence, myth, construction or reality?]. Paris, France: L'Harmattan.

Mintzberg, H. (1990). Le management. Voyage au centre des organisations [Management. Insights from within of organizations]. (J. Behar, Trans.) Paris, France: Organisation.

Perrin, J. (1999). Pilotage et évaluation des processus de conception [Piloting and assessment of design processes]. (Editions l'Harmattan, Ed.) Paris, France.

Prasad, B. (1996). Concurrent engineering fundamentals (Vol. 1). Upper Saddle River, New Jersey, USA: Prentice Hall.

Retour, D. (2002, Automne). Le management des compétences, quoi de neuf pour l'entreprise ? [Management of competences, what's new for the company?]. Management et Conjoncture Sociale, pp. 7-8.

Robin, V., Merlo, C., \& Girard, P. (2007). PEGASE: A prototype of software to manage design system in a collaborative design environment, in Complex Systems Concurrent Engineering: Collaboration, Technology Innovation and Sustainability. In L. Geilson, \& R. Curran (Ed.), 14th ISPE International Conference on Concurrent Engineering (pp. 597-604). Sao Jose dos Campos, Brazil: Springer.

Roucoules, L., Noel, F., Teissandier, D., Lombard, M., Debarbouille, G., Girard, P., \& Merlo, C. (2006). IPPOP: an open source collaborative design platform to link product, design process and industrial organisation information. 6th International Conference on Integrated Design and Manufacturing in Mechanical Engineering, IDMME'06. Grenoble, France.

Veltz, P., \& Zarifian, P. (1994). Travail collectif et modèles d'organisation de la production [Collective work and models of organization of production]. Le Travail Humain, 57(3), 239-249.

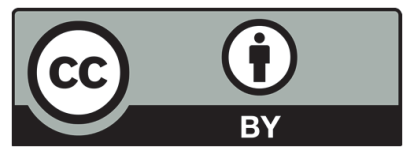

(C) 2020 by the authors; licensee Growing Science, Canada. This is an open access article distributed under the terms and conditions of the Creative Commons Attribution (CC-BY) license (http://creativecommons.org/licenses/by/4.0/). 